\title{
Editor's Desk
}

\section{What Do We Know}

\section{About Social-Media Marketing?}

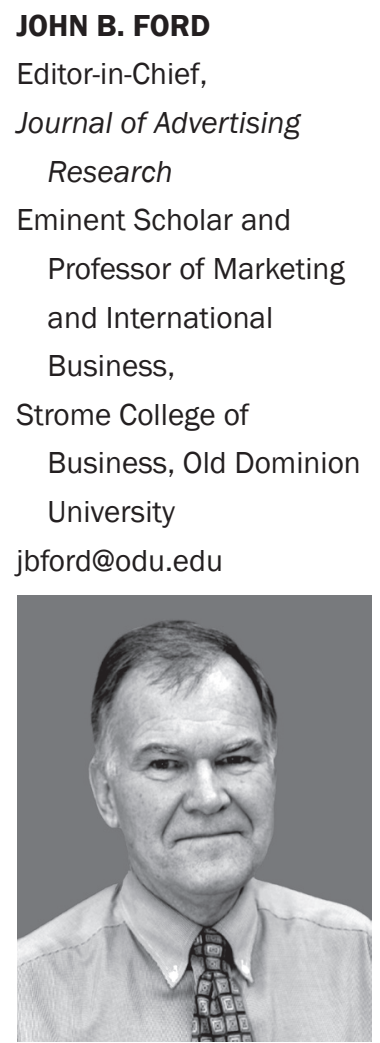

As the field of marketing research grows ever more diverse, it's imperative that the stewards of thought leadership speak with a clear, consistent, and succinct voice. To that end, the editors of the Journal of Advertising Research have regularly refined a series of formal Guidelines for Contributors.

To make sure that we are delivering papers that provide utility to our readers, we periodically update our editorial standards - a process that reflects our own research on how to best to serve our audience of both academicians and marketing professionals.

As we seek to provide a rich mix of content, we first need to better monitor the length of papers in these pages. Although there may be a rare exception to one new rule, we have set a cap of 7,000 words-including references, addenda, etc.-for publication of any paper. We certainly will screen papers that exceed that limit, but we will insist that authors revise their work accordingly.

As arbitrary as this may seem at first glance, our loyalty must be to our large constituency of readers and not to any individual author. The upside is obvious: By publishing more tightly constructed papers, we will be able to offer more points of research in every issue. And that, clearly, is in the best interests of our entire community of readers.

A second Guidelines revision is more qualitative: In a rapidly evolving research environment, where life expectancy of social-media vehicles is uncertain, we have learned that short-term media studies may not have the staying power to be of lasting interest to our readers. The strength of any academic journal rests in its long-term utility. In its 60 years of publication, the Journal has proven to be most useful when it eschews the brightest and shiniest-but also most transitory - topics and trends. To that end, we will re-focus our editorial efforts to feature work with more lasting applicability for advertising academicians and practitioners.
As a part of that effort, we encourage submissions of strong conceptually focused papers that present fresh ways of understanding marketing research industry. New tools have led to new practices. And new practices demand new research that will deliver long-term understanding anchored in both the compelling argumentation and logical explanation that long have been staples of this journal.

We encourage our readers and subscribers to review the full set of Guidelines, found in the back of every issue and on our website (http:// www.journalofadvertisingresearch.com/content/ submit-manuscript). With the refinements we've put into place, we hope to be able to increase the number of meaningful papers we publish in each issue and provide more potential long-lasting value for our readers.

The fiercest competition outside the game itself is the social-media battle for attention for eyes that occurs before, during, and after the Super Bowl. As the cost for 30 seconds of ad time has skyrocketed to more than $\$ 5$ million, marketers are challenged to discover new ways to deliver their messages to America's biggest audience. In "The Impact of Airing Super Bowl Television Ads Early on Social Media: Benefits and Drivers of Watching, Liking, and Sharing Advertisements on Social Media" (please see page 391), Jennifer Lee Burton (University of Tampa), Kristen M. Mueller (Accent Your Style Boutique), Jan Gollins (Delta Modelling Group), and Danielle M. Walls (BDJ Solutions) find that "the publicity benefits associated with purchasing a Super Bowl advertisement cannot be argued, but there is much debate surrounding the early release of Super Bowl advertisements on social media."

The paper-an integral part of a "What We Know about Social-Media Marketing" section-is 
grounded in a study of 650 consumers from 46 different states wherein the authors found substantial evidence that "prior social-media engagement with an advertising campaign does not spoil the surprise or novelty of a Super Bowl advertisement."

Addressing the need for marketers to deliver a message that lasts beyond its immediate in-game context, the paper discloses "the mere-exposure effect found by the authors (i.e., the tendency to rate advertisements higher on subsequent viewings) was more pronounced when that previous exposure occurred on social media ... Managers should create advertisements in which the peak level of affect occurs earlier in the advertisement, lasts longer, and ends near the conclusion of the advertisement to ensure maximum effectiveness."

On other fields of social-media play, "How Measuring Consumer Conversations Can Reveal Advertising Performance" (please see page 433), Brad Fay, Ed Keller, and Rick Larkin (all from Engagement Labs) carefully examined a variety of metrics-among them YouTube views, online WOM, offline WOM, and Google searches following the Super Bowl-to determine the messaging impact for the 23 advertisers whose messages were part of the 2019 Super Bowl broadcast.

The authors suggest that "measuring conversational uplift for brands can be an important indicator of whether an advertisement has hit the right target, delivered a relevant message, created brand identification, and sparked a response that leads someone to consider a purchase and share that reaction with others."

Somewhat surprisingly, they also discovered "there was strong WOM response to more routine advertising occasions, particularly when it was possible to compare uplifts in conversation for those exposed versus those not exposed to the advertisements." They conclude by stating that "advertisers have reason to expect effective advertising will drive conversations year-round."

For many consumers, Facebook is the first face of social media.

“How Do Brands' Facebook Posts Induce Consumers' e-Wordof-Mouth Behavior? Informational versus Emotional Message Strategy: A Computational Analysis" (please see page 402), by Taemin Kim (Incheon National University), Hyejin Kim (DePaul University), and Yunhwan Kim (Hankuk University of Foreign Studies), examines brand posts for 46 Fortune 100 companies to understand what aspects of brand posts predict consumer eWOM. The authors suggest that "companies should craft brand posts on Facebook carefully by incorporating informational and emotional aspects of a brand in parallel to induce consumers' eWOM behaviors effectively ... Post positivity (i.e., the level of positivity in a brand post) as an emotional message strategy also was found to exert negative effects on generating positive comments."
Facebook also is the focus of "Consumers' Responses to Facebook Advertising across PCs and Mobile Phones: A Model for Assessing the Drivers of Approach and Avoidance of Facebook Ads" (please see page 414), by Caroline Lancelot Miltgen (Audencia Business School), Anne-Sophie Cases (University of Montpellier), and Cristel Antonia Russell (Pepperdine University).

After collecting data from 287 Facebook enthusiasts in France, the authors found that "distinguishing between advertising's intrinsic value and its social value reveals differences in how value emerges as a function of the primary device used to access Facebook." For those using mobile phones, "an advertisement must provide a real service in facilitating ease of localization and access ... Facebook advertisements had greater social value for those users who consulted the network on their PCs."

In terms of avoidance and intrusiveness, the paper concludes that "trust in Facebook was a major driver of advertising acceptance overall and an important protective element in terms of reducing advertisements' perceived intrusiveness on mobile devices." The authors further urge practitioners to note that "trust plays slightly different roles as a function of the device used: In the PC environment, trust in the network enhanced acceptance of advertising by increasing users' perceived value, and in the mobile environment, trust in the network reduced perceptions of invasiveness and intrusiveness."

Yet another paper in our social-media package, "The Perceived Fit between Instagram Influencers and the Endorsed Brand: How Influencer-Brand Fit Affects Source Credibility and Persuasive Effectiveness" (please see page 440) reported the outcomes of two studies that recruited users of Facebook and Instagram to determine if "higher levels of perceived source credibility, in turn, led to higher indications of positive behavioral intentions." Authors Priska Linda Breves, Nicole Liebers, Marina Abt, and Annika Kunze (all from University of Würzburg) found that "participants who indicated high levels of parasocial relationship less likely based their assessment of the influencer's credibility on perceived fit; rather, they were inclined more to use their former experiences as an indication."

The research findings further noted that it might be possible for a popular endorser to endorse a brand that does not perfectly match their profile. They cautioned, however that the endorser should "try to incorporate high levels of authenticity into his or her posts to elicit high levels of parasocial relationship (e.g., by addressing the audience directly and telling a personal story."

$$
* * *
$$

As always, as the Journal of Advertising Research continues to grow and evolve, I welcome your feedback. 